\section{JURNAL EKONOMI EFEKTIF}

ISSN : $2622-8882$, E-ISSN : 2622-9935

Jurnal Ekonomi Efektif, Vol. 1, No. 4, Juli 2019

@Prodi Manajemen Fakultas Ekonomi Universitas

Pamulang

\title{
PENGARUH BOPO TERHADAP RETURN ON ASSET PADA PT. BANK MUAMALAT, TBK
}

\author{
Sahroni \\ Universitas Pamulang, Tangerang Selatan, Banten, Indonesia \\ *dosen01420@unpam.ac.id
}

\begin{abstract}
ABSTRAK
Penelitian ini bertujuan untuk mengetahui pengaruh BOPO terhadap Return On Asset pada PT. Bank Muamalat, Tbk. Metode yang digunakan adalah explanatory research. Teknik analisis menggunakan analisis statistik dengan pengujian regresi, korelasi, determinasi dan uji hipotesis. Hasil penelitian ini variabel BOPO diperoleh nilai rata-rata sebesar $80,46 \%$. Variabel Return On Asset diperoleh nilai rata-rata 3,27\%. BOPO berpengaruh positif dan signifikan terhadap Return On Asset dengan nilai persamaan regresi $\mathrm{Y}=-0,540+0,048 \mathrm{X}$, dan nilai koefisien korelasi 0,690 atau memiliki tingkat hubungan yang kuat dengan nilai determinasi 47,6\%. Uji hipotesis diperoleh signifikansi $0,000<0,05$.
\end{abstract}

\section{Kata Kunci: BOPO, Return On Asset.}

\section{ABSTRACT}

This study aims to determine the effect of BOPO on Return On Asset at PT. Bank Muamalat, Tbk. The method used is explanatory research. The analysis technique uses statistical analysis with regression testing, correlation, determination and hypothesis testing. The results of this study, the BOPO variable obtained an average value of $80.46 \%$. The return on assets variable obtained an average value of $3.27 \%$. BOPO has a positive and significant effect on Return On Assets with the regression equation $Y=-0.540+0.048 X$, and a correlation coefficient value of 0.690 or has a strong level of relationship with a determination value of 47.6\%. Hypothesis testing obtained a significance of $0.000<0.05$.

\section{Keywords: BOPO, Return On Asset.}




\section{PENDAHULUAN}

\section{A. Latar Belakang Masalah}

Pada dekade tahun 1980-an Indonesia pernah mengalami resesi dimana kondisi tersebut juga berimbas pada industri perbankan seperti (1) tingkat kepercayaan masyarakat dalam dan luar negeri terhadap perbankan di Indonesia menurun drastis; (2) sebagian besar bank dalam keadaan tidak sehat; (3) terjadi „negative spread ${ }^{\text {‘ }}$; (4) munculnya penggunaan peraturan perundangan yang baru; dan (5) jumlah bank menurun (Muhamad, 2005). Sehubungan dengan kondisi-kondisi yang dialami oleh perbankan tersebut, maka muncul suatu sistem perbankan alternatif yaitu bank syariah. Sistem bank syariah ini dapat membantu memulihkan perekonomian dengan sistem kemitraan dan kebersamaan (sharing) dalam profit dan risk sehingga kegiatan perekonomian akan lebih adil dan transparan. Untuk itu, dibentuklah UU No 10 tahun 1998 yang memberikan landasan kelembagaan dan operasional perbankan syariah secara komprehensif.

Kegiatan operasional bank syariah di Indonesia dimulai pada tahun 1992 melalui pendirian PT. Bank Muamalat Indonesia, Tbk yang dinobatkan sebagai bank umum syariah pertama di Indonesia. Dalam perkembangannya sejak BMI terbentuk, industry perbankan syariah di Indonesia semakin berkembang. Pada awalnya bank syariah di Indonesia hanya tercatat sebanyak tiga buah, namun kini pertumbuhannya semakin meningkat. Indikator dari kinerja suatu perusahaan salah satunya adalah profitabilitas. Profitabilitas merupakan kemampuan manajemen dalam menghasilkan laba. Salah satu proksi yang tepat untuk mengukur profitabilitas suatu bank adalah dengan melihat besar kecilnya Return On Asset (ROA), ini menunjukan kemampuan bank dalam menghasilkan income dari pengelolaan aset yang dimilikinya.

Kinerja bank syariah dapat dinilai melalui berbagai macam variabel yang diambil dari laporan keuangan bank syariah. Laporan keuangan tersebut menghasilkan sejumlah rasio keuangan yang dapat membantu para pemakai laporan keuangan dalam menilai kinerja bank syariah.

Tabel 1. Perkembangan BOPO dan ROA PT. Bank Muamalat, Tbk Periode 2010-2019.

\begin{tabular}{|c|c|c|}
\hline Tahun & BOPO (\%) & ROA (\%) \\
\hline 2010 & 57.42 & 2.27 \\
\hline 2011 & 82.64 & 2.78 \\
\hline 2012 & 83.64 & 3.42 \\
\hline 2013 & 81.38 & 3.37 \\
\hline 2014 & 75.68 & 3.58 \\
\hline 2015 & 69.73 & 2.68 \\
\hline 2016 & 87.66 & 2.98 \\
\hline 2017 & 92.24 & 3.88 \\
\hline 2018 & 85.52 & 3.45 \\
\hline 2019 & 88.77 & 4.86 \\
\hline Rata-rata & 80.47 & 3.33 \\
\hline
\end{tabular}

Dilihat pada BOPO juga mengalami ketidakstabilan setiap tahunnya dimana sempat megalami penurunan dari tahun 2014 sampai dengan tahun 2015 yang cukup baik namun di tahun 2016 mengalami kenaikan. Secara rata-rata mencapai 80,47 per tahun. Rasio BOPO ini memiliki fungsi untuk mengukur tingkat efisiensi dan kemampuan bank dalam melakukan kegiatan operasinya. Jika rasio ini rendah maka kinerja bank yang bersangkutan menunjukan tingkat efisiensi yang tinggi pada perusahaan (Riyadi, 2006).

BOPO (Belanja Operasional terhadap Pendapatan Operasional) merupakan rasio yang menggambarkan efisiensi perbankan dalam melakukan kegiatannya. Belanja operasional adalah biaya bunga yang diberikan pada nasabah sedangkan pendapatan 
operasional adalah bunga yang didapatkan dari nasabah. Semakin kecil nilai BOPO artinya semakin efisien perbankan dalam beroperasi

Dari ke dua variabel di atas mempengaruhi fluktuasi nilai ROA, pencapai nilai laba terendah dialami tahun 2010 yang hanya mampu memperoleh $2,27 \%$ dan nilai laba tertinggi dicapai tahun 2019 yang mampu mencapai 4,86\%. Dari 10 tahun terakhir rata-rata dicapai $3,33 \%$ per tahun. Tingkat efisiensi bank dalam menjalankan operasinya berpengaruh terhadap tingkat pendapatan yang dihasilkan oleh bank.

Dari fenomena yang diungkapkan di atas maka peneliti tertarik untuk melakukan penelitian tentang profitabilitas perbankan yaitu Return On Asset (ROA). Penelitian ini menggunakan variabel dependen ROA dan CAR, BOPO sebagai variable independen, dengan judul "Pengaruh BOPO Terhadap Return On Asset Pada PT. Bank Muamalat, Tbk Periode 2010-2019”.

\section{B. Rumusan Masalah}

1. Bagaimana BOPO pada pada PT. Bank Muamalat, Tbk?.

2. Bagaimana Return On Asset pada PT. Bank Muamalat, Tbk?.

3. Adakah pengaruh antara BOPO terhadap Return On Asset pada PT. Bank Muamalat, Tbk $?$.

\section{Tujuan Penelitian}

1. Untuk mengetahui kondisi BOPO pada PT. Bank Muamalat, Tbk.

2. Untuk mengetahui kondisi Return On Asset pada PT. Bank Muamalat, Tbk.

3. Untuk mengetahui pengaruh antara BOPO terhadap Return On Asset pada PT. Bank Muamalat, Tbk.

\section{METODE PENELITIAN}

\section{Populasi}

Populasi dalam penelitian ini laporan keuangan PT. Bank Muamalat, Tbk selama 10 tahun

\section{Sampel}

Teknik pengambilan sampling dalam penelitian ini adalah samplel jenuh, dimana semua anggota populasi dijadikan sebagai sampel. Dengan demikian sampel dalam penelitian ini laporan keuangan PT. Bank Muamalat, Tbk selama 10 tahun.

\section{Jenis Penelitian}

Jenis penelitian yang dipakai adalah kuantitatif, dimana tujuannya adalah untuk mengetahui mencari keberpengaruhan antara variabel independen terhadap variabel dependennya.

\section{Metode Analisis Data}

Dalam menganalisis data digunakan uji validitas, uji reliabilitas, analisis regresi linier sederhana, koefisien korelasi, koefisien determinasi dan uji hipotesis.

\section{HASIL PENELITIAN}

\section{Analisis Deskriptif}

Pada pengujian ini digunakan untuk mengetahui skor minimum dan maksimum skor tertinggi, ratting score dan standar deviasi dari masing-masing variabel. Adapun hasilnya sebagai berikut:

Tabel 1. Hasil Analisis Descriptive Statistics

\section{Descriptive Statistics}




\begin{tabular}{lr|r|r|r|r} 
& $\mathrm{N}$ & \multicolumn{1}{c}{ Minimum } & Maximum & \multicolumn{1}{c}{ Mean } & \multicolumn{1}{c}{ Std. Deviation } \\
\hline BOPO & 10 & 57.42 & 92.24 & 80.468 & 10.3805 \\
\hline ROA & 10 & 2.27 & 4.86 & 3.327 & .7227 \\
\hline Valid N (listwise) & 10 & & & & \\
\hline
\end{tabular}

Nilai BOPO diperoleh nilai minimum sebesar 57,42\% dan nilai maximum $92,24 \%$ dengan rata-rata sebesar $80,46 \%$ dengan standar deviasi $410,38 \%$.

Sedangkan nilai Return On Asset diperoleh nilai minimum sebesar 2,27\% dan nilai maximum 4,86\% dengan rata-rata sebesar 3,27\% dengan standar deviasi $0,72 \%$.

\section{Analisis Verifikatif.}

Pada analisis ini dimaksudkan untuk mengetahui pengaruh variabel independen terhadap variabel dependen. Adapun hasil pengujian sebagai berikut:

\section{a. Analisis Regresi Linier Sederhana}

Uji regresi ini dimaksudkan untuk mengetahui perubahan variabel dependen jika variabel independen mengalami perubahan. Adapun hasil pengujiannya sebagai berikut:

Tabel 2. Hasil Pengujian Regresi Linier Sederhana

\begin{tabular}{|c|c|c|c|c|c|c|}
\hline \multicolumn{7}{|c|}{ Coefficients $^{a}$} \\
\hline \multirow{2}{*}{\multicolumn{2}{|c|}{ Model }} & \multicolumn{2}{|c|}{$\begin{array}{l}\text { Unstandardized } \\
\text { Coefficients }\end{array}$} & \multirow{2}{*}{$\begin{array}{l}\text { Standardized } \\
\text { Coefficients } \\
\text { Beta }\end{array}$} & \multirow[b]{2}{*}{$t$} & \multirow[b]{2}{*}{ Sig. } \\
\hline & & $\mathrm{B}$ & Std. Error & & & \\
\hline \multirow[t]{2}{*}{1} & (Constant) & -.540 & 1.444 & & -.374 & .718 \\
\hline & BOPO & .048 & .018 & .690 & 2.698 & .027 \\
\hline
\end{tabular}

a. Dependent Variable: ROA

Berdasarkan hasil pengujian pada tabel di atas, diperoleh persamaan regresi $\mathrm{Y}=$ $0,540+0,048 X$. Dari persamaan tersebut dijelaskan sebagai berikut:

1) Konstanta sebesar -0,540 diartikan jika BOPO tidak ada, maka telah terdapat nilai Return On Asset sebesar -0,540 point.

2) Koefisien regresi BOPO sebesar 0,048, angka ini positif artinya setiap ada peningkatan BOPO sebesar 0,048 point maka Return On Asset juga akan mengalami peningkatan sebesar 0,048 point.

\section{b. Analisis Koefisien Korelasi}

Analisis koefisien korelasi dimaksudkan untuk mengetahui tingkt kekuatan hubungan dari variabel independen terhadap variabel dependen baik secara parsial maupun simultan. Adapun hasil pengujian sebagai berikut:

Tabel 3. Hasil Pengujian Koefisien Korelasi BOPO Terhadap Return On Asset.

\section{Correlations $^{b}$}

\begin{tabular}{llr|r} 
& \multicolumn{2}{c}{ BOPO } & \multicolumn{2}{c}{ ROA } \\
\hline BOPO (X2) & Pearson Correlation & 1 & $.690^{*}$ \\
\cline { 2 - 4 } & Sig. (2-tailed) & & .027 \\
\hline \multirow{2}{*}{ ROA } & Pearson Correlation & $.690^{*}$ & 1 \\
\cline { 2 - 4 } & Sig. (2-tailed) & .027 & \\
\hline
\end{tabular}

*. Correlation is significant at the 0.05 level (2-tailed).

b. Listwise $\mathrm{N}=10$

Berdasarkan hasil pengujian diperoleh nilai korelasi sebesar 0,690 artinya BOPO memiliki hubungan yang kuat terhadap Return On Asset.

\section{c. Analisis Koefisien Determinasi}

Analisis koefisien determinasi dimaksudkan untuk mengetahui besarnya persentase 
pengaruh dari variabel independen terhadap variabel dependen. Adapun hasil pengujian sebagai berikut:

Tabel 4. Hasil Pengujian Koefisien Determinasi BOPO Terhadap Return On Asset.

\begin{tabular}{|c|c|c|c|c|}
\hline \multicolumn{5}{|c|}{ Model Summary } \\
\hline Model & $\mathrm{R}$ & R Square & $\begin{array}{l}\text { Adjusted R } \\
\text { Square }\end{array}$ & $\begin{array}{l}\text { Std. Error of the } \\
\text { Estimate }\end{array}$ \\
\hline 1 & $.690^{\mathrm{a}}$ & .476 & .411 & .55466 \\
\hline
\end{tabular}

a. Predictors: (Constant), BOPO

Berdasarkan hasil pengujian diperoleh nilai determinasi sebesar 0,476 artinya BOPO memiliki kontribusi pengaruh sebesar 47,6\% terhadap Return On Asset, sedangkan sisanya sebesar $52,4 \%$ dipengaruhi faktor lain.

\section{d. Uji Hipotesis}

Pengujian hipotesis dengan uji $\mathrm{t}$ digunakan untuk mengetahui hipotesis mana yang diterima.

Rumusan hipotesis: Terdapat pengaruh yang signifikan antara BOPO terhadap Return On Asset.

Tabel 5. Hasil Uji Hipotesis BOPO Terhadap Return On Asset.

\begin{tabular}{|c|c|c|c|c|c|c|}
\hline \multicolumn{7}{|c|}{ Coefficients ${ }^{a}$} \\
\hline \multirow{2}{*}{\multicolumn{2}{|c|}{ Model }} & \multicolumn{2}{|c|}{$\begin{array}{l}\text { Unstandardized } \\
\text { Coefficients }\end{array}$} & \multirow{2}{*}{$\begin{array}{c}\text { Standardized } \\
\text { Coefficients } \\
\text { Beta }\end{array}$} & \multirow[b]{2}{*}{$\mathrm{t}$} & \multirow[b]{2}{*}{ Sig. } \\
\hline & & $\mathrm{B}$ & Std. Error & & & \\
\hline & (Constant) & -.540 & 1.444 & & -.374 & .718 \\
\hline & BOPO & .048 & .018 & .690 & 2.698 & .027 \\
\hline
\end{tabular}

a. Dependent Variable: ROA

Berdasarkan hasil pengujian pada tabel di atas, diperoleh nilai $\mathrm{t}$ hitung $>\mathrm{t}$ tabel atau $(2,698>2,306)$, dengan demikian hipotesis yang diajukan bahwa terdapat pengaruh yang signifikan atara BOPO terhadap Return On Asset diterima.

\section{Pembahasan Hasil Penelitian}

\section{Kondisi Nilai Variabel BOPO}

Berdasarkan data empiris dan analisis data, variabel BOPO diperoleh nilai rata-rata per tahun sebesar $80,46 \%$.

\section{Kondisi Nilai Variabel Return On Asset}

Berdasarkan data empiris dan analisis data, variabel Return On Asset diperoleh nilai ratarata per tahun sebesar $3,27 \%$.

\section{Pengaruh BOPO Terhadap Return On Asset}

BOPO berpengaruh signifikan terhadap Return On Asset dengan persamaan regresi Y $=-0,540+0,048 \mathrm{X}$, nilai korelasi sebesar 0,690 atau memiliki hubungan yang kuat dengan kontribusi pengaruh sebesar $47,6 \%$, sedangkan sisanya sebesar $52,4 \%$ dipengaruhi faktor lain. Pengujian hipotesis diperoleh nilai $t$ hitung $>t$ tabel atau $(2,698>2,306)$. Dengan demikian hipotesis yang diajukan bahwa terdapat berpengaruh signifikan antara BOPO terhadap Return On Asset diterima.

\section{KESIMPULAN DAN SARAN}

\section{Kesimpulan}


a. Kondisi variabel BOPO berdasar pada periode laporan keuangan 10 tahun diperoleh BOPO rata-rata sebesar $80,46 \%$.

b. Kondisi variabel Return On Asset berdasar pada periode laporan keuangan 10 tahun diperoleh BOPO rata-rata sebesar 3,27\%.

c. BOPO berpengaruh signifikan terhadap Return On Asset dengan persamaan regresi $\mathrm{Y}=$ $-0,540+0,048 \mathrm{X}$, nilai korelasi sebesar 0,690 atau kuat dan kontribusi pengaruh sebesar $47,6 \%$ sedangkan sisanya sebesar 52,4\% dipengaruhi faktor lain. Uji hipotesis diperoleh nilai $\mathrm{t}$ hitung $>\mathrm{t}$ tabel atau $(2,698>2,306)$.

\section{Saran}

Berdasarkan hasil analisis dan kesimpulan penelitian ini, maka ada beberapa temuantemuan yang kiranya dapat menjadi bahan saran bagi pihak- pihak terkait, adapun saran yang diberikan sebagai berikut:

a. Pihak manajemen bank agar lebih memperhatikan likuiditas dan menjaga keseimbangan modal perusahaan pada bank dan lebih meningkatkan perolehan laba pada perusahaan dalam kegiatannya.

b. Tingkat BOPO pada PT Bank Muamalat Indonesia masih belum mencapai standar yang telah ditetapkan oleh Bank Indonesia yakni 85\%. Kiranya pihak perbankan perlu mempertimbangkan aspek Biaya Operasional yang dikeluarkan dan meningkatkan kembali Pendapatan yang masuk guna meminimalisir resiko suatu perusahaan perbankan.

c. Bagi peneliti selanjutnya disarankan untuk melakukan penelitian di luar 239ariable 239ariable239nt yang digunakan dalam penelitian ini ataupun mengkombinasikan salah satu vaiabel dalam penelitian ini dengan vaiabel lain diluar 239ariable dalam penelitian ini, agar dapat memperoleh hasil yang lebih bervariatif yang dapat menggambarkan hal-hal apa saja yang dapat berpengaruh terhadap Return On Assets.

\section{DAFTAR PUSTAKA}

Agus Harjito \& Martono, (2010) "Manajemen Keuangan" Yogyakarta: Penerbit Ekonisia.

Agus Sartono. (2010). "Manajemen Keuangan Toeri dan Aplikasi", Edisi keempat, Yogyakarta: Penerbit BPFE.

Algifari. (2015). “Analisis Regresi untuk Bisnis dan Ekonomi”. Yogyakarta: BPFE.

Arikunto, Suharsimi (2014). "Prosedur Penelitian Suatu Pendekatan Praktek". Jakarta: Rineka Cipta.

Bambang Riyanto, (2011). "Dasar-dasar Pembelanjaan Perusahaan". Edisi ke empat, BPFE Yogyakarta.

Fahmi, Irham (2012), "Pengantar Manajemen Keuangan” Cetakan pertama. Bandung: Penerbit Alfabeta.

Imam Ghozali (2017). "Aplikasi Analisis Multivariate Dengan Program SPSS”. Edisi Kelima. Semarang: Badan Penerbit Undip.

Istijanto (2014) "Riset Sumber Daya Manusia". Jakarta: PT. Gramedia Pustaka

Jasmani, J. (2018). Pengaruh Kinerja Keuangan Terhadap Harga Saham (Analisis Pada Perusahaan Property dan Real Estate Yang Go Public di Bursa Efek Indonesia. Jurnal Akuntansi Indonesia, 12(2).

Kasmir (2010), "Analisis Laporan keuangan”, penerbit raja grafindo persada, Jakarta

Kasmir, (2010). "Pengantar Manajemen Keuangan", Edisi Pertama, Cetakan kedua, Jakarta:

Penerbit Prenada Media. 
Kasmir. (2012) “Pengantar Manajemen Keuangan”, Edisi Pertama, Cetakan kedua, Jakarta: Prenada Media.

Martono dan Agus Harjito, (2011). "Manajemen Keuangan", Jakarta: Penerbit Ekonisia..

Munawir (2010), "Analisis Laporan Keuangan", Edisi Ke Empat, Penerbit Liberty, Yogyakarta.

Santoso, Singgih (2015). "Menguasai Statistik Multivariat". Jakarta: PT Elex Media Komputindo.

Sartono, "Manajemen Keuangan Aplikasi Dan Teori", Edisi Keempat, BPFE, Yogyakarta, 2008.

Sawir, (2003). “Analisis Kinerja Keuangan dan Perencanaan Keuangan Perusahaan”, Cetakan ketiga, Jakarta: Penerbit PT. Gramedia Pustaka Utama.

Sugiyarso, G. dan F. Winarni, "Manajemen Keuangan (Pemahaman Laporan Keuangan, Pengelolaan Aktiva, Kewajiban dan Modal serta Pengukuran

Sugiyono (2017), "Metode Penelitian Administrasi : dilengkapi dengan Metode R \& D". Bandung: Alfabeta.

Yuangga, K. D., \& Sunarsi, D. (2018). The Influence of Procrastination and Low Time Management on Student Self Efficacy (at MA Soebono Mantofani). PINISI Discretion Review, 2(1), 85-92 